Original Article

\title{
Assessment of Sleep Quality of University Students
}

Munaza Bibi

Bahria University Karachi.

Corresponding Author: Munaza.12star@yahoo.com

\begin{abstract}
Objective To assess the sleep quality of university students of Karachi, and its association with mobile phone use, depression and academic performance. Methodology A random cross sectional study was conducted on 221 students and data was collected from different universities of Karachi business students. Results show that depression, mobile phone use impact on sleep quality thus affect the academic performance of students. About $38.9 \%$ students were nondepressed and $61.1 \%$ students were depressed. Sleep quality score shows that $8.6 \%$ students had good sleep and $91.4 \%$ had poor sleep, academic performance is measured in terms of last semester GPA (38\%) students had GPA 2.6-3.00, (30.3\%) students had GPA 3.1-3.5, (15.4\%) students had GPA 3.6-4.00, (14.5\%) students had GPA2.1-2.5 and (1.8\%) students' had GPA $<2.0$. In terms of mobile phone use, $(23.1 \%)$ students spend $<5$ hours, $(19.9 \%)$ spend 6-8 hours, $(24 \%)$ spend 9-10 hours and (33\%) spend $>10$ hours on mobile phone. Conclusion For the development and growth of this asset "sleep" is a very important aspect vital for normal functioning of physical and mental health of students. There is a need to control sleep problems and prevent its complications through proper counselling of students about the significance of sleep. Good quality of sleep can develop better academic, physical and psychological performance of university students.
\end{abstract}

\section{Keywords}

Sleep quality, Depression, Academic performance, Mobile phone use

\section{Introduction}

There are two categories of normal sleep first one is non-rapid eye movement (NREM) and second one is rapid eye movement (REM), further splitting up of (NREM) further divided into deep stages of sleep: stage N1, stage N2 and Stage N3. Need strong stimulus by NREM sleep for awakening. Phasic component of REM sleep which is resolute sympathetically by rapid eye movements, respiratory variation and twitches in muscle. REM sleep tonic component is Para sympathetically determined with no movement of eyes. Sleep (NREM) followed by sleep (REM) which occurs between 4-5 times during 8 hours of normal sleep. Stage N3 in which presence of sleep in first third and REM sleep during the last third of the night. NREM problem such sleep walking occur in the presence of N3 stage of sleep along with first third during night. Stage N1 is the time between alert and sleep it account for $2-5 \%$ of sleep. Stage N2 is present throughout the sleep time, it accounts for 45$55 \%$ of the whole sleep. Unconsciousness a physiologic condition in sleep in which brain is more receptive to both (internal and external) stimulus. During sleep brain is less reactive to senses (visual and auditory) and external stimulus during the period from conscious to sleep (Steven M.S. et al, 2015). There are two processes which control the sleep, the wake system process $\mathrm{S}$ endorse sleep and process $\mathrm{C}$ (circadian) that preserve alertness is stimuli across day to neutralize with process $S$ for restlessness and alertness during the day. Process $\mathrm{C}$ is falling to prop up the sleep (process $\mathrm{S}$ ). 
The process $\mathrm{S}$ (homeostatic) of sleep is regulated by neurons, by invigorating the brain to promote the sleep. These neurons are there in Hypothalamus (pre-optic area) accountable to turn off the awakening system during the sleep time. The brainstem ascending system is accountable for sleeplessness. It has two main paths that move on the way from the brain stem, the first path; originate from cholinergic neurons in the upper Pons, which in reaction activates the thalamus for conduction of sensory nerves (information) to cerebral cortex. The second path, originates in the upper brainstem (cell groups) enter Hypothalamus as an alternative of thalamus upper brain stem contains the mono amine transmitters nor epinephrine, serotonin, dopamine and histamine .In Hypo thalamus it receives the inputs from nerve cells that include (melanin concentrating hormones and peptides),information traverse the forebrain (basal area) by getting inputs from acetylcholine and gamma - amino butyric acid containing cells, all information go through the cerebral cortex it provoke the nerve cells ( Harvey R.\& Bruce, 2006).

An inside biological regulator of sleep in body is circadian rhythm, accountable for sleep and sleeplessness cycle in human beings. Circadian rhythm sustains the duration of sleep and restlessness per the day time and night. The process of bringing together of physiologic purpose with day night time called as photo entrainment. As the light changes into dark receptors sense these changes with encouragement of super chiasmatic nucleus (SCN) which contain 20,000 nerve cells which activates the neurons where axons move down to the sympathetic (pre ganglionic) neurons in the lateral horn of spinal cord. Post ganglionic axons direct to pineal gland (present in dorsal thalamus) generates the sleep promoting neuro hormones melatonin. Melatonin level increases between 2:00 -4:00 A.M. Aberration in melatonin creation lead to sleep difficulty (Purves D. et al., 2001). One of the major physiologic process of human body is sleep, around $25-40 \%$ of young people experience sleep problem (Lazaratou $\mathrm{H}$. et al., 2005 \& Garcia L.M.A. et al., 2004). Study in China showed $16.9 \%$ adults suffering from sleep problem (Liu X. et al., 2000). Sleep plays an important role for the health and affecting stability of individuals, poor sleep affects emotions in the outward appearance of depression (Kimberly. O' et al., 2016). Digital media use (including computer \& mobile phone) among university students prior to sleep negatively effect on sleep. Good sleep is necessary for proper functioning of body physical \& mental health of students (Kathryn .M. et al., 2016). Study showed that depression, pressures for academic performance and anxiety among university students result in inadequate quality of sleep (Seblewngel. L. et al., 2012).

Study showed that respondents who left their mobile phone in switch on form had poor quality of sleep in relation to those who kept their mobile phone in switch off manner (Yen - S. L.et al., 2016). Association between depression and sleep quality can be a problem, especially for female students with volatility of emotional aspect were diagnosed as sleep deprived than in association with male students (Seoyoun K. et al., 2016). 1st year medical students gave more importance to studies workloads, pressures, and pressure about absence of response and 3rd year students gave high score to reservations about their future, in year 6th students gave high score to not accommodating academic climate". Predominance of depression among students of medicine was $12.9 \%$ and along with female students it was $16.9 \%$ and $8.1 \%$ 
amongst male students. Study showed that students of medicine experienced more depression than other people (Marie. D. et al., 2005). Ideation of suicides rate be found higher among university students of South Africa. Depression, tension and anxiety eventually forecast suicidal ideation among students of South Africa than ordinary population (Jason R. et al., 2016). 71.1\% participants experienced sleeplessness and the nightmares rate of occurrence was modest problem among student's population were about two per fourteen days, increased psychiatric symptoms are linked with sleep problems, circadian rhythm hindrance and nightmares (Sheaves B. et al., 2015).

\section{Methodology}

The study design was Cross sectional study conducted at one point in time or over a short period of time. The Target population for this study was business students of different universities of Karachi. A sample size of 221 students, including both male and female. Non-probability, convenience sampling method was used for this study Instruments for this research was a well-structured questionnaire, prepared by using multi item Likert scale, Part1: questionnaire ascertained demographic information of respondents like gender, age, education, and department. Part 2: comprised of the questions regarding depression, sleep quality, academic performance and mobile phone use in university students of Karachi. (PSQI) is selfrated questionnaire which evaluate the sleep quality. The PSQI dealings with seven areas: subjective sleep quality, latency, extent, routine sleeps efficiency, sleeps disorder, utilization of sleeping medicines, and daytime dysfunction over the last month. PSQI consist of seven components scores ranging from (0-3), 0 score is good and 3 score is very bad. The total score $>5$ indicate sleep problems and $<5$ indicate no sleep problem. CES-D is a questionnaire which is self-rated to quantify the depression symptoms in common population. CES-D score is the summation of 20 items; each piece is scored from $0-3$. A score of 16 and above is well thought-out as depression. Collected Data was analyzed using SPSS v. 16.

\section{Results}

The reliability of overall questionnaire value is .720 which is greater than 0.5 so the questionnaire used for this research is reliable. A random cross - sectional study was conducted, Results shows the association with depression, mobile phone use on sleep quality thus affect the academic performance of students. CES-D score shows that $38.9 \%$ students were non-depressed and $61.1 \%$ students were depressed. Sleep quality score (PSQI) shows that $8.6 \%$ students had good sleep and $91.4 \%$ had poor sleep, academic performance is measured in terms of last semester GPA (38\%) students had GPA 2.63.00, (30.3\%) students had GPA 3.1-3.5, (15.4\%) students had GPA 3.6-4.00, (14.5\%) students had GPA2.1-2.5 and (1.8\%) students had GPA <2.0. In terms of mobile phone use, (23.1\%) students spend <5 hours, $(19.9 \%)$ spend 6-8 hours, (24\%) spend 9-10 hours and $(33 \%)$ spend $>10$ hours on mobile phone. A substantial proportion of subjects were sleep deprived and depressed, and increase use of mobile phone and related technologies reflecting the poor sleep quality trend in university students. Graphical representations are given below: 
Figure1 shows PSQI Score.

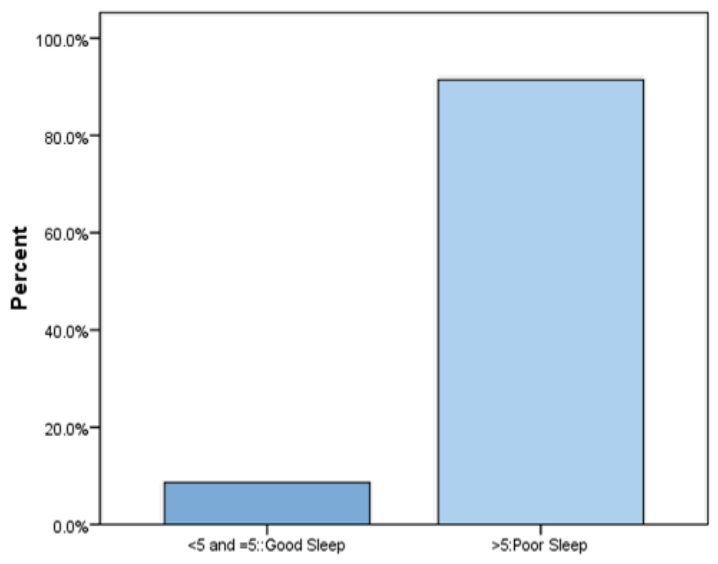

Figure2 shows Depression Score.

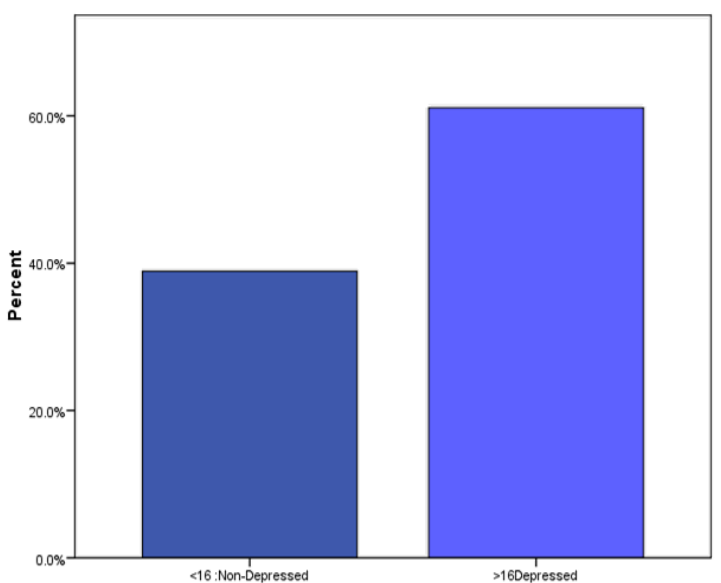

Figure3 shows Last Semester GPA.

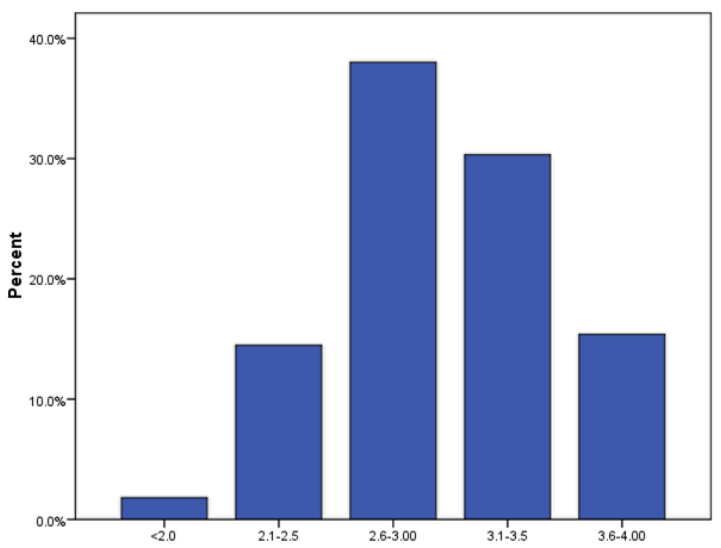

Figure4 shows Time Spend on Mobile Phone.

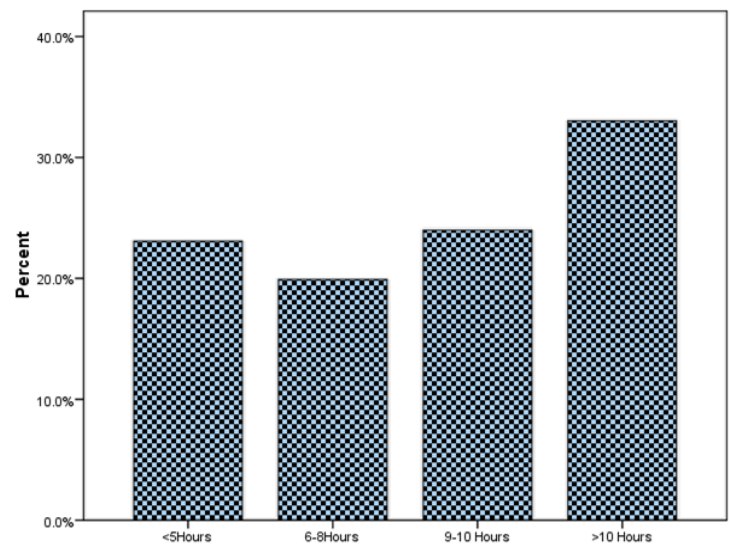

\section{Discussion}

This study was done to assess the sleep quality of university students of Karachi. Subjects involved in this study were mainly business students. Students with poor sleep quality score had poor cognitive performance and depression. Poor sleep is considered as a key symptom to cause changes in neurotransmitters as a result it leads to depression among adults (David; 2010). (CES-D) score p- value is 0.001 which is less than 0.005 , it shows association between depression and sleep quality of university students. Based on CES -D 61.1\% students had depression and $38.9 \%$ were not depressed, by treating depression is likely to improve poor to good sleep quality (Nour, et al., 2016). $91.4 \%$ of the students in reality had poor sleep quality and $8.6 \%$ had good sleep quality, poor sleep quality has an association with decrease mental health and performance of students (Henrick, et al., 2007). For evaluating association between mobile phone use and sleep quality, students were asked how much time students spend on mobile phone, majority of students spend more time on mobile phone which ultimately affect their sleep (Teresa, et al., 2016). Mobile phone use indicates p-value is 0.002 which is less than 
0.005 it is significant showing association between mobile phone use and sleep quality.

In terms of mobile phone use, $(23.1 \%)$ students spend $<5$ hours, $(19.9 \%)$ spend 6-8 hours, (24\%) spend 9-10 hours and (33\%) spend $>10$ hours on mobile phone, excessive use of mobile affect sleep among students also claimed that Use of internet, online playing of game with mobile, sports and hitech sophisticated gadgets was associated with reduced sleep quality including sleeplessness. $33 \%$ students had difficulty in sleep after mobile phone use. Academic performance $\mathrm{p}$-value is 0.001 which is less than 0.005 which also show significant association between academic performance and sleep quality (Eyvazlou, et al., 2016 \& Lam L.T, 2014). A considerable connection was found between lower GPAs and lack of sleep. Academic performance is measured in terms of last semester GPA (38\%) students had GPA 2.6-3.00, (30.3\%) students had GPA 3.1-3.5, (15.4\%) students had GPA 3.6$4.00,(14.5 \%)$ students had GPA2.1-2.5 and (1.8\%) students had GPA <2.0 (Kelly, et al; 2001).

An association between well sleep measures as a measurement of academic performance. Delayed bed timetable was linked with reduced academic performance in terms of CGPA among young person (Mari, et al., 2016). Strong association was found between sleep troubles and reduced academic performance and educational behaviors (Jorge, et al., 2016). Students with poor sleep quality score had poor academic performance as compared to those with good sleep, poor sleep eventually influences the academic performance (Karl, et al.,2015).

\section{Conclusion}

From the results and studies it can be assayed that "sleep" is a very important aspect vital for normal functioning of physical and mental health of students. Systemic interference is fundamental to promote healthy practice in the family, addressing in particular, and use of mobile phone, study pattern and sleep behaviors that impacts on sleep quality of student's. There is a need to control sleep problems and depression to prevent its complications through proper counselling of students about the significance of sleep and cognitive health for good academic performance. Good quality of sleep can develop better academic, physical and psychological performance of university students.

\section{Recommendations}

Future studies should spotlight on detecting poor sleep quality causes and impact of sleep on suicidal ideation in order to understand possible interaction and co - morbidities and use longitudinal designs to comprehend the influence of these considered variables.

\section{Acknowledgement}

I would like to acknowledge my research supervisor \& teacher Mumtaz Khan (Bahria University), who encourage me and support me in writing of this paper.

\section{Conflict of Interest}

No competing interests were found in the preparation of this paper.

\section{References}

- Altevogt, B. M., \& Colten, H. R. (Eds.). (2006). Sleep disorders and sleep deprivation: an unmet public health problem. National Academies Press.

- Bantjes, J. R., Kagee, A., McGowan, T., \& Steel, H. (2016). Symptoms of posttraumatic stress, depression, and anxiety as predictors of suicidal ideation among South African university students. Journal of American college health, 64(6), 429-437. 
- Choueiry, N., Salamoun, T., Jabbour, H., El Osta, N., Hajj, A., \& Khabbaz, L. R. (2016). Insomnia and relationship with anxiety in university students: A crosssectional designed study. PloS one, 11(2), e0149643.

- Dahlin, M., Joneborg, N., \& Runeson, B. (2005). Stress and depression among medical students: A cross-sectional study. Medical education, 39(6), 594-604.

- Eyvazlou, M., Zarei, E., Rahimi, A., \& Abazari, M. (2016). Association between overuse of mobile phones on quality of sleep and general health among occupational health and safety students. Chronobiology international, 33(3), 293-300.

- Garcia-Jimenez, M. A., Salcedo-Aguilar, F., Rodriguez-Almonacid, F. M., Redondo-Martínez, M. P., MonterdeAznar, M. L., Marcos-Navarro, A. I., \& Torrijos-Martínez, M. P. (2004). The prevalence of sleep disorders among adolescents in Cuenca, Spain. Revista de neurologia, 39(1), 18-24.

- Hysing, M., Harvey, A. G., Linton, S. J., Askeland, K. G., \& Sivertsen, B. (2016). Sleep and academic performance in later adolescence: results from a large population-based study. Journal of sleep research, 25(3), 318-324.

- Kelly, W. E., Kelly, K. E., \& Clanton, R. C. (2001). The relationship between sleep length and grade-point average among college students. College Student Journal, 35(1), 84-86.

- Kim, S., Park, J., Kim, H., Kim, T. K., Min, Y., Kim, J., \& Yang, J. (2016). How much does depressive mood affect sleep for high school students? European Psychiatry, 33, S742.

- Lam, L. T. (2014). Internet gaming addiction, problematic use of the internet, and sleep problems: a systematic review. Current psychiatry reports, 16(4), 444.

- Lazaratou, H., Dikeos, D. G., Anagnostopoulos, D. C., Sbokou, O., \& Soldatos, C. R. (2005). Sleep problems in adolescence A study of senior high school students in Greece. European child \& adolescent psychiatry, 14(4), 237-243.

- Lee, Y. S., \& Low, B. S. (2016). Sleep pattern among electronic device users and its relationship with users' practice in Malaysia university community. Sleep and Biological Rhythms, 14(3), 271-277.

- Lemma, S., Gelaye, B., Berhane, Y., Worku, A., \& Williams, M. A. (2012). Sleep quality and its psychological correlates among university students in Ethiopia: a cross-sectional study. BMC psychiatry, 12(1), 237.

- Liu, X., Uchiyama, M., Okawa, M., \& Kurita, H. (2000). Prevalence and correlates of self-reported sleep problems among Chinese adolescents. Sleep: Journal of Sleep Research \& Sleep Medicine.

- Lizandra, J., Devís-Devís, J., PérezGimeno, E., Valencia-Peris, A., \& PeiróVelert, C. (2016). Does sedentary behavior predict academic performance in adolescents or the other way round? A longitudinal path analysis. PloS one, 11(4), e0153272.

- Minges, K. E., \& Redeker, N. S. (2016). Delayed school start times and adolescent sleep: a systematic review of the experimental evidence. Sleep medicine reviews, 28, 86-95.

- Nutt, D., Wilson, S., \& Paterson, L. (2008). Sleep disorders as core symptoms of depression. Dialogues in clinical neuroscience, 10(3), 329.

- O'Leary, K., Small, B. J., Panaite, V., Bylsma, L. M., \& Rottenberg, J. (2017). Sleep quality in healthy and mooddisordered persons predicts daily life 
emotional reactivity. Cognition and Emotion, 31(3), 435-443.

- Orzech, K. M., Grandner, M. A., Roane, B. M., \& Carskadon, M. A. (2016). Digital media use in the $2 \mathrm{~h}$ before bedtime is associated with sleep variables in university students. Computers in human behavior, 55, 43-50.

- Paiva, T., Gaspar, T., \& Matos, M. G. (2016). Mutual relations between sleep deprivations, sleep stealers and risk behaviours in adolescents. Sleep Science, 9(1), 7-13.

- Pallos, H., Gergely, V., Yamada, N., Miyazaki, S., \& Okawa, M. (2007). The quality of sleep and factors associated with poor sleep in Japanese graduate students. Sleep and Biological Rhythms, 5(4), 234-238.

- Purves, D., Augustine, G. J., Fitzpatrick, D., Katz, L. C., LaMantia, A. S., McNamara, J. O., \& Williams, S. M. (2001). Neurotransmission in the Visceral Motor System.

- Sheaves, B., Porcheret, K., Tsanas, A., Espie, C. A., Foster, R. G., Freeman, D., \& Goodwin, G. M. (2016). Insomnia, nightmares, and chronotype as markers of risk for severe mental illness: results from a student population. Sleep, 39(1), 173181.

- $\quad$ Steven M.S., Benbadis S.R. \& Armon C. 2015. Normal sleep, sleep physiology, and sleep deprivation. Medscape. 